\title{
A rare case of omental metastasis as first and singular site of failure from localized prostate cancer
}

\author{
Nazmeen Shameem ${ }^{* 1}$, Andrej Bece ${ }^{1}$, Martin Stockler ${ }^{2,3}$, Charbel Sandroussi ${ }^{4,5}$, Geoff Watson ${ }^{6}$, George Hruby ${ }^{2,7}$ \\ ${ }^{1}$ Department of Radiation Oncology, Chris O'Brien Lifehouse, Sydney, Australia \\ ${ }^{2}$ Faculty of Medicine, University of Sydney, Australia \\ ${ }^{3}$ Department of Medical Oncology, Concord Hospital, Sydney, Australia \\ ${ }^{4}$ Department of Hepatobiliary, Upper Gl and Transplant Surgery, Royal Prince Alfred Hospital, Sydney, Australia \\ ${ }^{5}$ University of New England, Northern Central New South Wales, Australia \\ ${ }^{6}$ Department of Tissue Pathology and Diagnostic Oncology, Royal Prince Alfred Hospital, Sydney, Australia \\ ${ }^{7}$ Department of Radiation Oncology, Royal North Shore Hospital, Sydney, Australia
}

Received: May 27, 2016

DOI: $10.5430 /$ crcp.v3n4p20
Accepted: June 5, $2016 \quad$ Online Published: July 7, 2016

URL: http://dx.doi.org/10.5430/crcp.v3n4p20

\begin{abstract}
The most common sites of metastases from prostate cancer are the regional lymph nodes and bones followed by lung, liver, pleura and adrenals. We describe an unusual presentation of metastatic prostate cancer with omental metastases as the only site of disease. An otherwise well 72-year-old man was investigated for a rising prostate specific antigen (PSA) 12 months after curative-intent radiotherapy and androgen deprivation for high risk prostate cancer. CT scans showed omental caking with no evidence of bony or other metastases. Omental biopsy demonstrated adenocarcinoma of prostatic origin.
\end{abstract}

Key Words: Prostate cancer, Omental metastasis, Case report

\section{INTRODUCTION}

The most common sites of metastases from prostate cancer include regional lymph nodes and bone followed by lung, liver, pleura and adrenals. ${ }^{[1]}$ Isolated peritoneal metastasis from prostatic acinar adenocarcinoma (presenting as omental caking) is extremely rare. We present the case of a patient with prostate cancer with omental metastasis in the absence of nodal or skeletal involvement.

\section{Case presentation}

\subsection{Background}

A fit and well 72-year-old man presented with a raised prostate specific antigen (PSA) of $23.5 \mu \mathrm{g} / \mathrm{L}$. The only sig- nificant family history was his father being diagnosed with bowel cancer. On digital rectal examination he had evidence of bilateral prostate infiltration (clinical stage T2c). He proceeded to trans-rectal ultrasound-guided prostate biopsies which demonstrated extensive Gleason 4+3 adenocarcinoma involving 14 of 14 cores (see Figure 1). His prostate volume was $41 \mathrm{ml}$. Staging with CT of the abdomen and pelvis and Technetium-99m bone scan did not demonstrate any evidence of metastases.

\subsection{Initial management}

The patient was managed with curative intent using neoadjuvant and concurrent short term androgen deprivation therapy

\footnotetext{
*Correspondence: Nazmeen Shameem, MBBS; Email: nazmeen.shameem@lh.org.au; Address: Chris O’Brien Lifehouse, Missenden Rd, Camperdown, NSW, Australia.
} 
(ADT) followed by radical external beam radiation treatment (46 Gy in 23 daily fractions) and high dose rate brachytherapy boost (19 Gy in 2 fractions of 8.5 Gy) using an Iridium-192 afterloader technique. ${ }^{[2]}$ ADT was with leuprolide (Eligard) for a duration of 6 months.

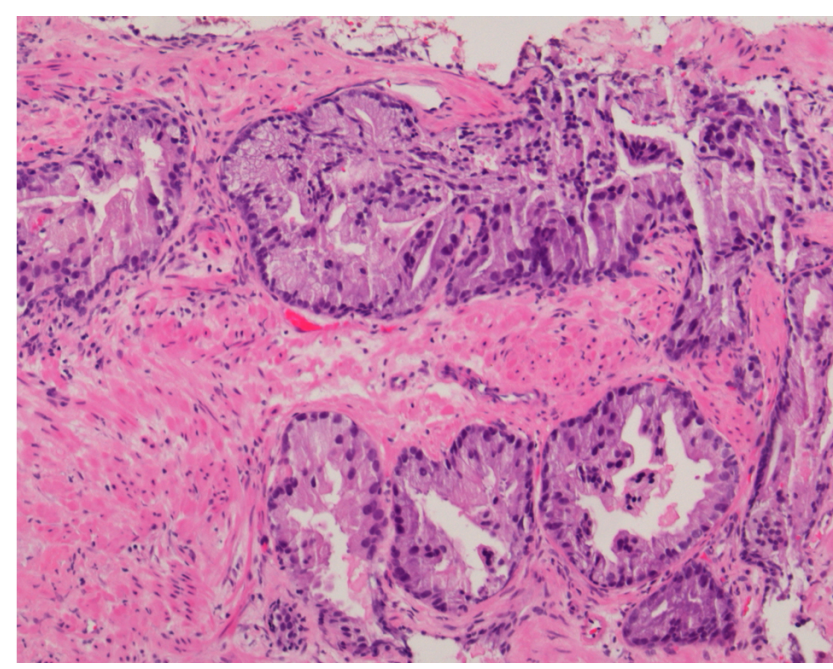

Figure 1. Trans-rectal prostate biopsy showing Gleason pattern 4

Seven weeks following radiotherapy the PSA was $0.2 \mu \mathrm{g} / \mathrm{L}$ showing a good response to treatment. However, 6 months after treatment his PSA had risen to $3.2 \mu \mathrm{g} / \mathrm{L}$. At this stage the patient was observed. Twelve months following treatment the PSA rose to $20 \mu \mathrm{g} / \mathrm{L}$ and he underwent re-staging with CT which revealed "omental caking" (see Figure 2). Bone scan was negative for osseous metastases. His CA 19-9 was in the normal range $(10 \mathrm{kU} / \mathrm{L})$.

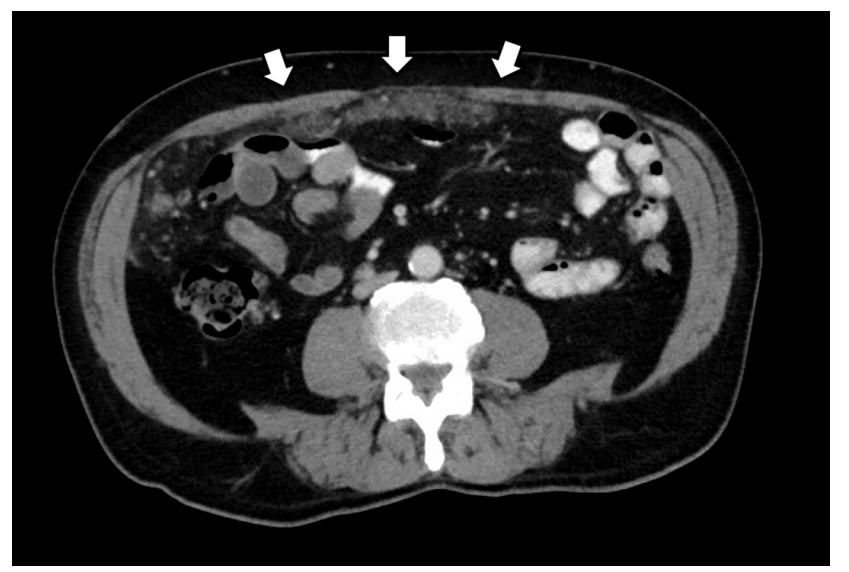

Figure 2. Computed tomographic scan of the abdomen showing diffuse omental caking (arrows)

On account of the omental disease, the case was presented and discussed at the Upper Gastro-Intestinal Multidisciplinary Meeting and the consensus was that the omental Published by Sciedu Press caking was likely from a gastrointestinal malignancy. He underwent a laparotomy and omental biopsies. The operative findings were of diffuse omental metastases without evidence of ascites.

\subsection{Histopathology}

The morphology of the omental specimen revealed fibroadipose tissue with tumour nodules. Microscopic features were consistent with metastatic acinar adenocarcinoma with single and fused complex glands lined by columnar epitheium with clear cell change within a desmoplastic stroma (see Figure 3).

The tumour was positive for PSA and ERG and negative for CK7, CK20, CDX2, TTF1 and GATTA3.

The tissue from the omental biopsy was compared to the original core biopsies by an anatomical pathologist experienced in genitourinary malignancy $(\mathrm{GW})$ and deemed to be the same tumour.

\subsection{Subsequent management}

Following the diagnosis, the patient was discussed with a genito-urinary medical oncologist and recruited to the ENZAMET randomised trial. ENZAMET is comparing the effectiveness of enzalutamide versus a conventional non-steroidal anti-androgen, when combined with a luteinising hormone releasing hormone (LHRH) analog as first line ADT for newly diagnosed metastatic prostate cancer. ${ }^{[3]}$ He was randomised to the control arm and commenced on leuprolide (Eligard) $45 \mathrm{mg}$ six-monthly and bicalutamide (Cosudex/Casodex) $50 \mathrm{mg}$ daily.

At the time of writing, the patient remains well. His most recent PSA was $0.10 \mu \mathrm{g} / \mathrm{L}$. Repeat CT of the abdomen and pelvis has shown a reduction in the volume of omental disease with no ascites or evidence of metastatic disease elsewhere. He continues on leuprolide and bicalutamide.

\section{Discussion}

The most common sites of metastatic spread of prostate cancer are the lymph nodes and the skeleton. To the best of our knowledge, an isolated presentation of omental caking alone as first and only site of dissemination from prostate cancer, in the absence of ascites, has never previously been reported.

In a recent review, 16 cases of prostate cancer presenting with ascites were described, 7 of which did not have evidence of disease beyond the peritoneum. ${ }^{[4]}$ Brehmer et al ${ }^{[5]}$ described a case of isolated peritoneal carcinomatosis at the time of pelvic lymphadenectomy for what was thought to be a localised prostate cancer. The other cases were all associated with ascites. There has been one case presented in 
2002 of mucin-producing adenocarcinoma metastasising to omentum, however this was associated with gross ascites. ${ }^{[6]}$ The patient responded well to surgical castration followed by hormonal manipulation. A second case report reported a patient with hormone refractory prostate cancer with peritoneal metastasis, again accompanied by ascites, but without bony metastases, who showed an excellent response to docetaxelbased chemotherapy. ${ }^{[7]}$ The only other case report of prostate cancer metastasising with extensive caking of the omentum, in which the disease caused a bowel obstruction, was in the setting of neuroendocrine differentiation. ${ }^{[8]}$

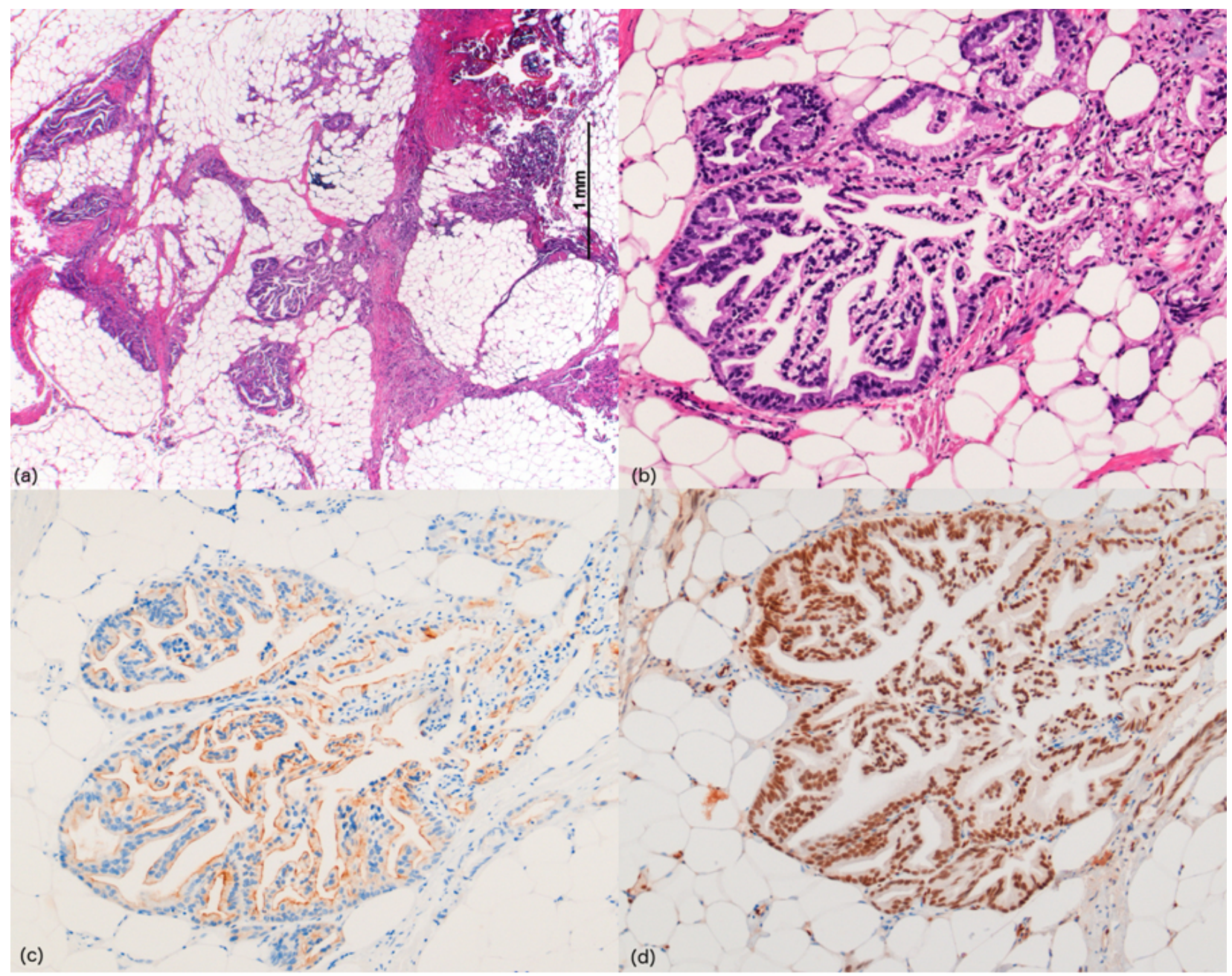

Figure 3. Omental biopsies, showing (a) spread pattern in the omentum at $2 \times$, (b) single and fused complex glands lined by columnar epithelium at $10 \times$, (c) positive staining for PSA, (d) positive staining for ERG.

This is therefore the only reported case of prostatic acinar adenocarcinoma causing omental caking as the initial and only site of metastasis.

\section{CONFlicts OF INTEREST Disclosure}

The authors declare no conflicts of interest.

\section{REFERENCES}

[1] Bubendorf L, Schoepfer A, Wafner U, et al. Metastatic patterns of prostate cancer: an autopsy study of 1,589 patients. Hum Pathol. 2000; 31(5): 578-83. PMid: 10836297. http://dx.doi.org/10. 1053/hp. 2000.6698

[2] Bece A, Patanjali N, Jackson M, et al. High-dose rate brachyther- apy boost for prostate cancer: Outcomes and genitourinary toxicity. Brachytherapy. 2015; 14(5): 670-6. http://dx.doi.org/10.10 $16 / j$. brachy .2015 .04 .004

[3] Australian and New Zealand Urogenital and Prostate Cancer Trials Group (ANZUP). Enzalutamide in First Line Androgen Deprivation Therapy for Metastatic Prostate Cancer (ENZAMET). In: 
ClinicalTrials.gov [Internet]. Bethesda (MD): National Library of Medicine (US). 2000- [cited 2016 Apr 26]. Available from: https : //clinicaltrials.gov/ct2/show/NCT02446405. NLM Identifier: NCT02446405.

[4] Petrakis D, Pentheroudakis G, Kamina S, et al. An unusual presentation of a patient with advanced prostate cancer, massive ascites and peritoneal metastasis: Case report and literature review. J Adv Res. 2015; 6(3): 517-21. http://dx.doi.org/10.1016/j.jare.20 14.05 .002

[5] Brehmer B, Makris A, Wellmann A, et al. Solitary peritoneal carcinomatosis in prostate cancer. Aktuel Urol. 2007; 38(5): 408-9. http://dx.doi.org/10.1055/s-2007-959185
[6] Kehinde EO, Abdeen SM, Al-Hunawan A, et al. Prostate cancer metastatic to the omentum. Scand J Urol Nephrol. 2002; 36(3): 2257. http://dx.doi.org/10.1080/003655902320131938

[7] Zagouri F, Papaefthimiou M, Chalazonitis AN, et al. Prostate cancer with metastasis to the omentum and massive ascites: a rare manifestation of a common disease. Onkologie. 2009; 32(12): 758-61. http://dx.doi.org/10.1159/000255336

[8] Wynn SS, Nagabundi S, Koo J, et al. Recurrent prostate carcinoma presenting as omental large cell carcinoma with neuroendocrine differentiation and resulting in bowel obstruction. Arch Pathol Lab Med. 2000; 124(7): 1074-6. PMid: 10888786. 